플 Sprience Press Springer-Verlag

\title{
Erratum to: Distribution of isotopes and chemicals in precipitation in Shule River Basin, northwestern China: an implication for water cycle and groundwater recharge
}

\author{
ZHAO Wei, MA Jinzhu*, GU Chunjie, QI Shi, ZHU Gaofeng, HE Jiahua
}

Key Laboratory of Western China's Environmental Systems (Ministry of Education), College of Earth Environmental Sciences, Lanzhou University, Lanzhou 730000, China

Published online: 14 October 2016

(C) Xinjiang Institute of Ecology and Geography, Chinese Academy of Sciences, Science Press and Springer-Verlag Berlin Heidelberg 2017

Erratum to: J Arid Land (2016) 8(6): 973-985

doi: 10.1007/s40333-016-0091-y

In this Erratum, we corrected the Figure 10 of "Distribution of isotopes and chemicals in precipitation in Shule River Basin, northwestern China: an implication for water cycle and groundwater recharge", which was published in Journal of Arid Land Vol. 8 No. 6 and was not a correct graphic. The correction is as follow:

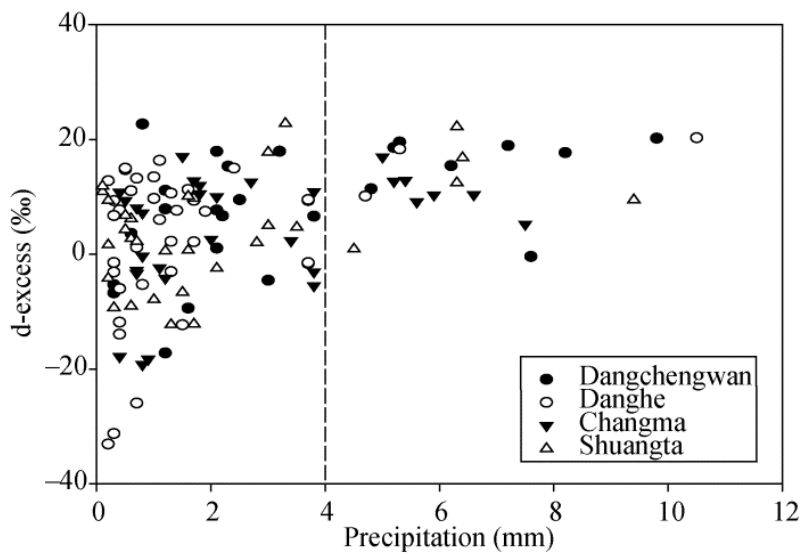

Fig. 10 Relationship between the daily d-excess values and the precipitation amount at the four sites

The online version of the original article can be found under doi: 10.1007/s40333-016-0091-y. 